\title{
Prediction of functional recovery by cardiac magnetic resonance feature tracking imaging in first time ST-elevation myocardial infarction. Comparison to infarct size and transmurality by late gadolinium enhancement
}

\author{
Sorin Giusca ${ }^{1 *}$, Birgit Krautz ${ }^{1}$, Yannick Sander ${ }^{1}$, Lukas Rust ${ }^{1}$, Christian Galuschky², Sebastian A Seitz ${ }^{1}$ \\ Evangelos Giannitsis ${ }^{1}$, Sven Pleger ${ }^{1}$, Philip Raake ${ }^{1}$, Patrick Most ${ }^{1}$, Grigorios Korosoglou ${ }^{1}$, Hugo Katus ${ }^{1}$, \\ Sebastian Buss ${ }^{1}$
}

From 18th Annual SCMR Scientific Sessions

Nice, France. 4-7 February 2015

\section{Background}

To investigate whether myocardial deformation imaging, assessed by a noninvasive post-processing feature tracking algorithm (FTI) on regular cardiac magnetic resonance (CMR) cine images, would allow objective quantification of regional and global left ventricular (LV) strain and provide the estimation of functional recovery in patients with first time ST-elevation myocardial infarction (STEMI).

\section{Methods}

Cardiac magnetic resonance (CMR) imaging was performed in 74 consecutive patients (mean age: $57 \pm$ 12yrs.) 2-4 days after successfully reperfused STEMI, using a $1.5 \mathrm{~T}$ whole body MR scanner (Philips Achieva). Peak systolic circumferential and longitudinal strain were measured using the feature tracking algorithm applied to SSFP cine sequences and were compared to infarct size, determined by late gadolinium enhancement (LGE). Follow-up CMR at 6 months after STEMI was performed in order to assess follow-up ejection fraction, which deemed as the reference standard for the estimation of function.

\section{Results}

Significant correlations were observed between global circumferential and longitudinal strain with infarct size by LGE $(r=0.75,95 \% C I=0.63-0.83$ and $r=0.45,95 \% C I=0.24-$ 0.61 , respectively). During the follow-up period 53 of 74 (72\%) patients exhibited preserved residual ejection fraction $\geq 50 \%$. A cut-off value of $-19.3 \%$ for global circumferential strain identified patients with preserved ejection fraction $\geq 50 \%$ at follow-up with sensitivity of $76 \%$ and specificity of $85 \%$ (AUC $=0.86,95 \% \mathrm{CI}=0.75-0.93, \mathrm{p}<0.001$ ), which was superior to that provided by longitudinal strain $(\triangle \mathrm{AUC}=0.13, \mathrm{SE}=0.05$, zstatistic $=2.5, \mathrm{p}=0.01)$, and noninferior to that provided by LGE ( $\triangle \mathrm{AUC}=0.07, \mathrm{p}=\mathrm{NS}$ ). Multivariate analysis showed that global circumferential strain and LGE exhibited independent value for the prediction of preserved LV-function, surpassing that provided by age, diabetes and baseline ejection-fraction $(\mathrm{HR}=1.4$, $95 \% \mathrm{CI}=1.0-1.9$ and $\mathrm{HR}=1.4,95 \% \mathrm{CI}=1.1-1.7$, respectively, $\mathrm{p}<0.05$ for both).

\section{Conclusions}

Estimation of circumferential strain by FTI provides objective assessment of infarct size without the need for contrast agent administration and estimation of functional recovery with non-inferior accuracy compared to that provided by LGE. 


\section{Funding}

N/A.

\section{Authors' details}

${ }^{1}$ Cardiology, University Hospital Heidelberg, Heidelberg, Germany. ${ }^{2}$ TomTec Imaging Systems, Munich, Germany.

Published: 3 February 2015

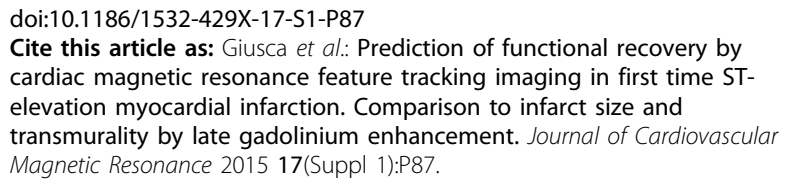

Submit your next manuscript to BioMed Central and take full advantage of:

- Convenient online submission

- Thorough peer review

- No space constraints or color figure charges

- Immediate publication on acceptance

- Inclusion in PubMed, CAS, Scopus and Google Scholar

- Research which is freely available for redistribution 